\title{
The Life Cycle of New spaper Coverage of a Public Issue: Candlelight Protests against US Beef Imports in South Korea*
}

\author{
Kimuck Park**
}

\begin{abstract}
This paper applies Downs's concept of the issue attention cycle and Hilgartner and Bosk's public arenas model to the competition among social problems for public attention. It draws on the recent controversy in Korea about the import of US beef to test the idea that a major issue has several issues and events related to it, and that this can explain why its life cycle is extended. The beef imports controversy involved one issue (concern about mad-cow disease) and four events (coverage of the disease on the PD Pocketbook TV show, police excess, intimidation of newspaper advertisers, and activity of the People's Council for Countermeasures against Mad-Cow Disease). Drawing on Hilgartner and Bosk's work, this study develops an issue competition model and uses it to estimate the decrease in media attention to this controversy. It found that the decrease in media attention resulted from competition from other issues.
\end{abstract}

Keywords: issue attention cycle, issue competition, candlelight rallies, mad-cow disease

\section{INTRODUCTION}

Social issues compete for attention in public arenas. Hilgartner and Bosk (1988) suggest that "public attention on social problems is a scarce resource, allocated through competition in a system of public arenas," which include "executive and legislative branches of government, the courts, made-for-TV movies, the cinema, the news media (television news, magazines, newspapers, and radio), political campaign organizations, social action groups, direct mail solicitations, books dealing with social issues." While the concept of competition for public attention was originally introduced by Gallie

* This research was supported by the Daegu University Research Grant, 2010.

** Kimuck Park is a professor in the College of Public Administration at Daegu University. He is currently working on modeling of the issue attention cycle. E-mail: kpark@ daegu.ac.kr.

Manuscript received January 6, 2012; out for review February 6, 2012; review completed February 23, 2012; accepted March 15, 2012.

The Korean Journal of Policy Studies, Vol. 27, No. 1 (2012), pp. 41-56.

(C) 2012 by the GSPA, Seoul National University 
(1962), Connolly (1983), and Blumer (1971), Hilgartner and Bosk (1988) applied it to the effect of public arenas on both the evolution of social problems and the actors who are interested in them.

Of the public arenas Hilgartner and Bosk (1988) introduced, the news media seem to play a greater role than others in attracting public attention to social events. The news media tend to define social problems based on these events and to communicate to a mass audience immediately. Media outlets also may keep on directing public attention to social events. Hilgartner and Bosk (1988) presented the concept that different social problems compete with each other for attention in public arenas, such as the news media, the courts, and government. They argue that public attention to social problems is not affected by the scale of the population of these problems and varies over time.

Today, a huge number of public events occur in our societies. Of these, only a small number succeed in attracting public attention. In order for an event to attract public attention, mass media coverage is essential (Gans 1979, 1980; McCombs, 2004; Molotch 1979; Molotch \& Lester, 1974; Oliver 1989; Oliver \& Maney 2000; Zald 1996). Saying that "the link between public events and the public sphere is the mass media," Oliver and Myers (1999) present a new view about the crucial role of the mass media in research on public events because of media sources for data about these public events. In recent years, scholars of public events have been able to draw on comprehensive article databases provided by many media outlets, particularly newspapers.

Public events seem to have a life cycle in terms of news media coverage. Downs's (1972) issue attention cycle model explains the cyclic processes of social issues in five steps: (1) the pre-problem stage, (2) alarmed discovery and euphoric enthusiasm (the stage at which the government intervenes), (3) realizing the cost of significant progress, (4) gradual decline of intense public interest, and (5) the post-problem stage. Four decades later, scholars continue to cite Downs's articles (Cram, 2001; Hall, 2002; Son \& Weaver, 2006).

According to Downs, citizens tend to easily tire of one issue and turn their attention to a new issue, so it is difficult for one issue to garner continuous interest. Downs sought to apply his model to ecological issues, which tend to require a long time to solve. The model can also be usefully applied to other political, economic, and social issues that share this attribute.

This paper applies Downs's issue attention cycle and Hilgartner and Bosk's public arenas model to the competition of social problems. It also borrows an idea from Oliver and Myers, who introduced a method for measuring newspaper coverage of public events. This paper suggests that a major issue has several related issues and events, 
and this explains why its life cycle is extended. Based on Hilgartner and Bosk's work, it develops an issue competition model and uses it to estimate the decrease in media attention to an issue.

In order to explain these ideas and develop and estimate the issue competition model, this paper focuses on the 2008 protests in Korea over imports of US beef. A number of candlelight vigils were held to protest the Lee Myung-Bak government's beef import deal with the United States because of fears about "mad cow" disease. These vigils attracted great attention from the media and the public for four months. They were held on weekends and public holidays at first, and eventually on weekdays as well. At first, health safety was the key issue; but as radical political groups became involved, protests increasingly targeted Korea's right-wing government and stimulated anti-American sentiment. Although the mad-cow disease issue remained central, the debate involved little scientific evidence. Beef imports had evolved into a social issue with deeply divided public opinion.

Like Downs's ecological issues, the beef imports issue seemed likely to take a long time to resolve. Because of its long-term nature, it offers an excellent context in which to apply Downs's model.

\section{EMPIRICAL OBSERVATIONS}

The life cycle of the US beef imports issue can be measured by observing the media's attention to it. Many researchers of media attention have emphasized that the media plays a pivotal role in making the population aware of controversial issues (Gamson \& Modigliani, 1989; Gamson \& Wolfsfeld, 1993; Kielbowicz \& Scherer, 1986; McCarthy, Mcphail, \& Smith, 1996; Olien, Tichenor, \& Donahue, 1992). The salience of the beef imports issue was also due to the media's attention to it.

The Korean government decided to resume US beef imports virtually without any restrictions in 2008. (South Korea had banned US beef imports in 2003 because of an outbreak of mad-cow disease in the United States.) In response, a civil alliance called the People`s Action for Countermeasures Against Mad-Cow Disease held candlelight vigils in central Seoul streets on May 2 and 3. Up to 10,000 people attended these vigils. Alarmed by spreading public protests against a government decision, police outlawed candlelight vigils to be held after the sunset. Agriculture Minister Chung Woon-Chun said in a press interview on May 2 that US beef is safe to eat. In response to the police's first confrontation and the agriculture minister's press interview, more people gathered in the center of Seoul for candlelight vigils. As time passed, the number of participants increased by up to 700,000 . 
The candlelight vigils started on April 21 were held until August 11. Thanks to communication via the Internet, the citizens who initiated the vigils were joined by young students and families. Participants were mostly ordinary citizens, but as some radical groups participated, the vigils occasionally developed into physical clashes with riot police, during which 500 police were injured and 173 police buses were destroyed. Also, 1,400 demonstrators were taken into custody and 31 were taken in detention.

\section{MEASURING MEDIA ATTENTION}

The life cycle of the beef imports issue can be measured in terms of media attention to it. Scholars have suggested various methods of measuring media attention (Hilgartner \& Bosk, 1988; Erbring, Goldenberg, \& Miller, 1980; Oliver \& Myers 1999). Hilgartner and Bosk (1988) suggested as the method of the measurement the amount of prime space in a newspaper: "the front pages of the sections, the editorial pages, and certain featured spots scattered throughout the paper." Oliver and Myers (1999) measured media coverage by using every article about public events that was found while searching by keywords in the computer database Nexis.

This study measured media attention to the beef imports issue based on the number of articles directly or indirectly related to it in six national daily newspapers in South Korea. Articles with a title related to the beef imports issue were classified as directly related, and other articles with content related to the issue were classified as indirectly related. ${ }^{1}$

\section{The Life Cycle of the Beef Imports Issue}

The beef imports issue had a life cycle of about four months, which was relatively long. Reasons for this long life included the long-standing national controversy on mad-cow disease and four events:

1. The TV program PD Pocketbook broadcast a distorted report about mad-cow disease in the United States.

1. The newspapers Dongailbo, Kukminilbo, Hankukilbo, Munhwailbo, Kyunghyang Shinmun, and Asiatoday were searched - using the Korea Integrated News Database System, the largest news search website in South Korea—with the search terms "mad cow disease" and "candlelight." 
2. The People's Council for Countermeasures against Mad-Cow Disease sponsored candlelight rallies.

3. The police used excessive force in suppressing the rallies.

4. Some radical protesters threatened companies that advertised in three conservative newspapers, the Chosun, Donga, and Joongang.

The national controversy over mad-cow disease was mostly focused on the security of US beef imports. It began to attract media attention from the start of the candlelight rallies and maintained this attention with fluctuations for more than three months. Since the discussion about US beef imports was related to the national health, it seemed to have a long period of media attention.

The staying power of the beef imports issue can be also explained by the four related events described above, which attracted media attention for some time. The occurrence of these dependent events played a role in raising media attention by making newspapers report them. Figure 1 shows the media attention cycle for the beef imports issue and the sum of media attention to other events, which included the national controversy on mad cow disease and four kinds of events.

As figure 1 shows, the life cycle of the beef imports issue largely depended on the media attention to the national controversy on mad cow disease and four kinds of events. Without these, it would not have received so much attention over such a long

Figure 1. The Life Cyde of the Beef Imports Issue and Media Attention to Other Events

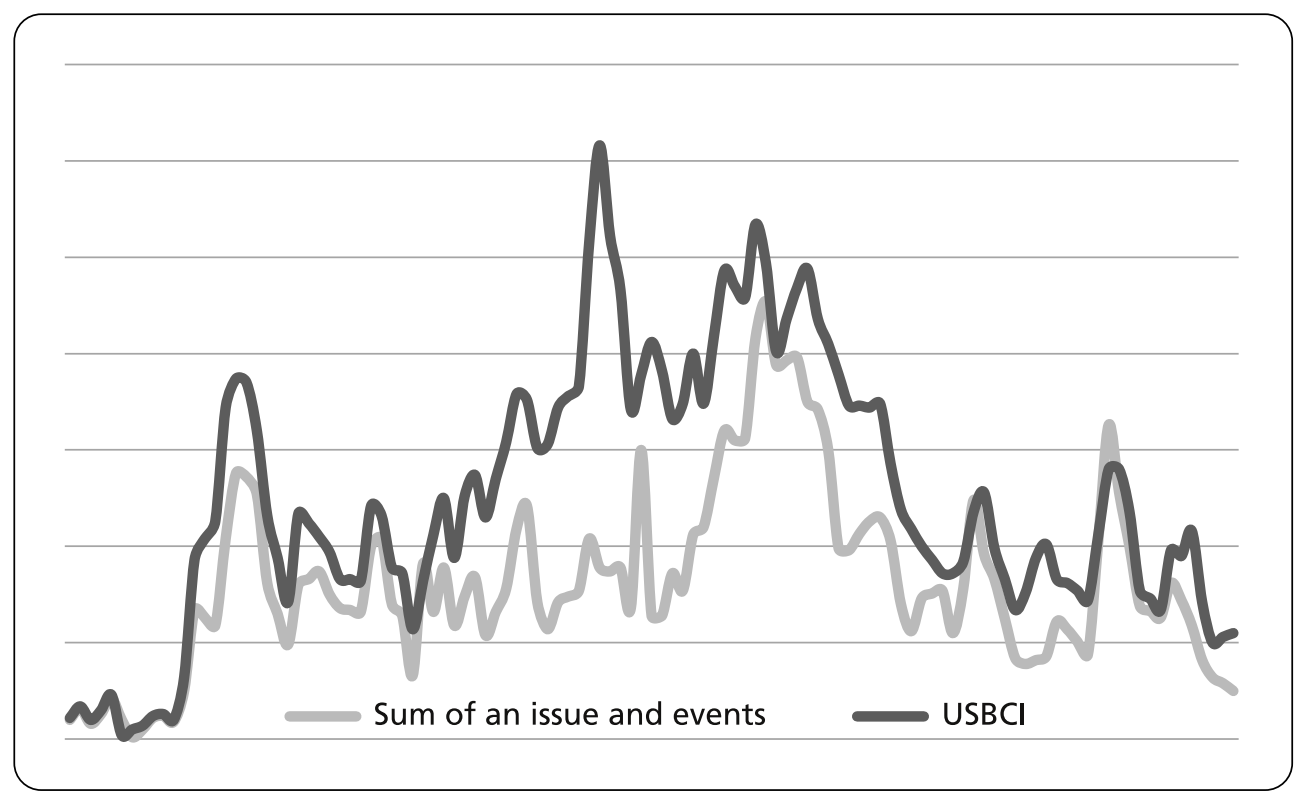


period.

Viewed as a graph, the life cycle of the beef imports issue looks much like the fluctuations in stock market prices, and is difficult to determine whether or not it has the shape of the Downs issue attention cycle. So rather than focusing on changes that occurred over a short period of time, the life cycle was typified according to the pattern that developed over a long period. However, because discerning the shape of the graph according to the naked eye can be subjective, this study investigates whether or not the graph has a Downsian shape by using the spline function method in order to ensure objectivity.

\section{The Spline Function Method}

The spline function uses a regression method that can measure and show significant changes in media attention levels (dependent variable) at a specific time point (independent variable). According to Suits et al. (1978), the spline function can be used to a system of piecewise polynomial approximations. In their spline functions, Suits et al. (1978) show that the $X$ axis, denoting an independent variable, can be separated into $\mathrm{k}_{+1}$ intervals by the points $\mathrm{X}_{0}, \mathrm{X}_{1}, \ldots, \mathrm{X}_{\mathrm{k}+1}$. The spline function can be transferred as a form of regression model.

$$
\mathrm{Y}=\mathrm{b}_{0}+\mathrm{b}_{1}\left(\mathrm{X}-\mathrm{X}_{0}\right)+\mathrm{c}_{1}\left(\mathrm{X}-\mathrm{X}_{0}\right)^{2}+\mathrm{d}_{1}\left(\mathrm{X}-\mathrm{X}_{0}\right)^{3}+\sum_{i=1}^{\varepsilon_{1}}\left(\mathrm{~d}_{\mathrm{i}+1}-\mathrm{d}_{\mathrm{i}}\right)\left(\mathrm{X}-\mathrm{X}_{\mathrm{i}}\right)^{3} \mathrm{D}_{\mathrm{i}}^{*}
$$

where $D_{i}^{*}$ is a dummy variable. Its value is 1 for all observations such that $X \geq X_{i}$, and is otherwise 0 .

If the life cycle has shown five intervals, we can obtain the multiple regression model as follows:

$$
\begin{aligned}
\mathrm{Y} & =\mathrm{b}_{0}+\mathrm{b}_{1}\left(\mathrm{X}-\mathrm{X}_{0}\right)+\mathrm{c}_{1}\left(\mathrm{X}-\mathrm{X}_{0}\right)^{2}+\mathrm{d} 1(\mathrm{X}-\mathrm{X} 0)^{3}+\left(\mathrm{d}_{2}-\mathrm{d}_{1}\right)\left(\mathrm{X}-\mathrm{X}_{1}\right)^{3} \mathrm{D}_{1}{ }^{*} \\
& +\left(\mathrm{d}_{3}-\mathrm{d}_{2}\right)\left(\mathrm{X}-\mathrm{X}_{2}\right)^{3} \mathrm{D}_{2}{ }^{*}+\left(\mathrm{d}_{4}-\mathrm{d}_{3}\right)\left(\mathrm{X}-\mathrm{X}_{3}\right)^{3} \mathrm{D}_{3}{ }^{*}+(\mathrm{d} 5-\mathrm{d} 4)(\mathrm{X}-\mathrm{X} 4)^{3} \mathrm{D}_{4}{ }^{*}
\end{aligned}
$$

where $b_{2}=c_{1}, b_{3}=d_{1}, b_{4}=\left(d_{2}-d_{1}\right), b_{5}=\left(d_{3}-d_{2}\right), b_{6}=\left(d_{4}-d_{3}\right)$, and $b_{7}=\left(d_{5}-d_{4}\right)$. This equation is a multiple regression on six composite variables. The regression procedure can be easily run by any least-squares regression package. Goodness of fit, significance tests, and other related statistics for the spline function can be obtained from the regression program. 


\section{Using the Spline Function to Determine the Media Attention Cycle of the Beef Imports Issue}

The aforementioned methods were applied to the beef imports issue in order to quantify the media's interest level, utilize the spline function to categorize the issue's life cycle pattern, and determine whether this issue corresponded with Downs's issue attention cycle model. As mentioned earlier, the media's interest in this issue from April 21 to August 11, 2008, was measured according to the number of related articles in six national daily newspapers in South Korea. Based on the research data, figure 1 depicts the media attention level on the Y-axis and time on the X-axis.

The beef imports issue attracted little attention for 11 days starting April 21, gained rapidly increasing attention for six days, and maintained a steady level of interest for three days. From May 10, media attention to the issue decreased by half and remained at that level until June 1. Then the media's interest rose rapidly, reached its peak on June 11, fluctuated around that level until July 1, and gradually declined to August 11, the end point for consideration in this study. ${ }^{2}$

Next, the data on media attention to the beef imports issue were processed with the spline function method to determine the shape of its life cycle. May 1, May 8, May 12, June 1 , June 11 , and July 1 were identified as periods of rapid change. Therefore, there are five intervals in the spline functions $\left(\mathrm{X}_{1}=\right.$ May $1, \mathrm{X}_{2}=$ May $12, \mathrm{X}_{3}=$ June $1, \mathrm{X}_{4}=$ June 11 , and $\mathrm{X}_{5}=\mathrm{July} 1$, with $\mathrm{X}$ representing media attention level). Because the media attention cycle has five intervals, the multiple regression model can be expressed as follows:

$$
Y=b_{0}+b_{1} Z_{1}+b_{2} Z_{2}+b_{3} Z_{3}+b_{4} Z_{4}+b_{5} Z_{5}+b_{6} Z_{6}+b_{7} Z_{7}+b_{8} Z_{8}
$$

where $b_{2}=c_{1}, b_{3}=d 1, b 4=\left(d_{2}-d_{1}\right), b_{5}=\left(d_{3}-d_{2}\right), b_{6}=\left(d_{4}-d_{3}\right), b_{7}=\left(d_{5}-d_{4}\right), Z_{1}=\left(X-X_{0}\right)$, $\mathrm{Z}_{2}=\left(\mathrm{X}-\mathrm{X}_{0}\right)^{2}, \mathrm{Z}_{3}=\left(\mathrm{X}-\mathrm{X}_{0}\right)^{3}, \mathrm{Z} 4=\left(\mathrm{X}-\mathrm{X}_{1}\right)^{3} \mathrm{D}_{1}{ }^{*}, \mathrm{Z}_{5}=\left(\mathrm{X}-\mathrm{X}_{2}\right)^{3} \mathrm{D}_{2}{ }^{*}, \mathrm{Z}_{6}=\left(\mathrm{X}-\mathrm{X}_{3}\right)^{3} \mathrm{D}_{3}{ }^{*}$, $\mathrm{Z}_{7}=\left(\mathrm{X}-\mathrm{X}_{4}\right)^{3} \mathrm{D}_{4}{ }^{*}$, and $\mathrm{Z}_{8}=\left(\mathrm{X}-\mathrm{X}_{5}\right)^{3} \mathrm{D}_{5}{ }^{*}$.

This multiple regression model is estimated by running a statistical program. Table 1 displays estimation results according to the spline function method.

2. Even though there continued to be media attention to the beef imports issue after August 11, the level of attention was a little lower or upper than 50. Thus, this paper did not consider media attention after August 11. 
Table 1. Estimation Results Based on the Spline Function

\begin{tabular}{c|c|c|c}
\hline $\begin{array}{c}\text { Independent variables } \\
\text { and constant }\end{array}$ & Regression coefficient & T value & Significance level \\
\hline Constant & 6.889 & 0.370 & 0.712 \\
\hline$Z_{1}$ & $2.104^{* *}$ & 2.260 & 0.026 \\
\hline$Z_{2}$ & -1.023 & -0.427 & 0.583 \\
\hline$Z_{3}$ & $135.469 * * *$ & 2.717 & 0.008 \\
\hline$Z_{4}$ & $133.938^{* * *}$ & 3.154 & 0.002 \\
\hline$Z_{5}$ & 0.061 & 0.021 & 0.984 \\
\hline$Z_{6}$ & $-68.776^{* * *}$ & -5.851 & 0.000 \\
\hline$Z_{7}$ & -3.158 & -1.550 & 0.124 \\
\hline$Z_{8}$ & $2.714^{* * *}$ & 3.372 & 0.001 \\
\hline
\end{tabular}

$* p<0.1 ; * * p<0.05 ; * * * p<0.01 . \mathrm{F}=46.624 . \mathrm{R}^{2}=0.671$.

In the spline function, media attention is the dependent variable $Y$, and there are five intervals. The coefficients of independent variables $\left(Z_{1}, Z_{2}, Z_{3}, \ldots ., Z_{8}\right)$ are estimated by multiple regression independent variables. We can express the results as

$$
\begin{aligned}
\mathrm{Y}= & 6.889+2.104 \mathrm{Z}_{1}^{* *}-1.023 \mathrm{Z}_{2}+135.469 \mathrm{Z}_{3}{ }^{* * *}+133.938 \mathrm{Z}_{4}{ }^{* * *}-0.061 \mathrm{Z}_{5}-68.776 \mathrm{Z}_{6}{ }^{* *} \\
& -3.158 \mathrm{Z}_{7}+2.714 \mathrm{Z}_{8}^{* * *} \\
& \left({ }^{*} \mathrm{p}<0.1 ;{ }^{* *} \mathrm{p}<0.05 ;{ }^{* * *} \mathrm{p}<0.01 . \mathrm{F}=46.624 . \mathrm{R}^{2}=0.671\right)
\end{aligned}
$$

The goodness of fit, F, of this spline function is 46.624, which implies almost 100 percent fitness, and the value of $\mathrm{R}^{2}$ implies that independent variables explain the dependent variable by 67.1 percent. And of the eight independent variables, five were found to be relevant. Thus, it can be said that this spline function describes the beef imports issue well. Figure 2 shows how well the estimation of this spline function depicts the issue's actual life cycle. 
Figure 2. Observed and Predicted Values of the Life Cycle of the Beef Imports Issue

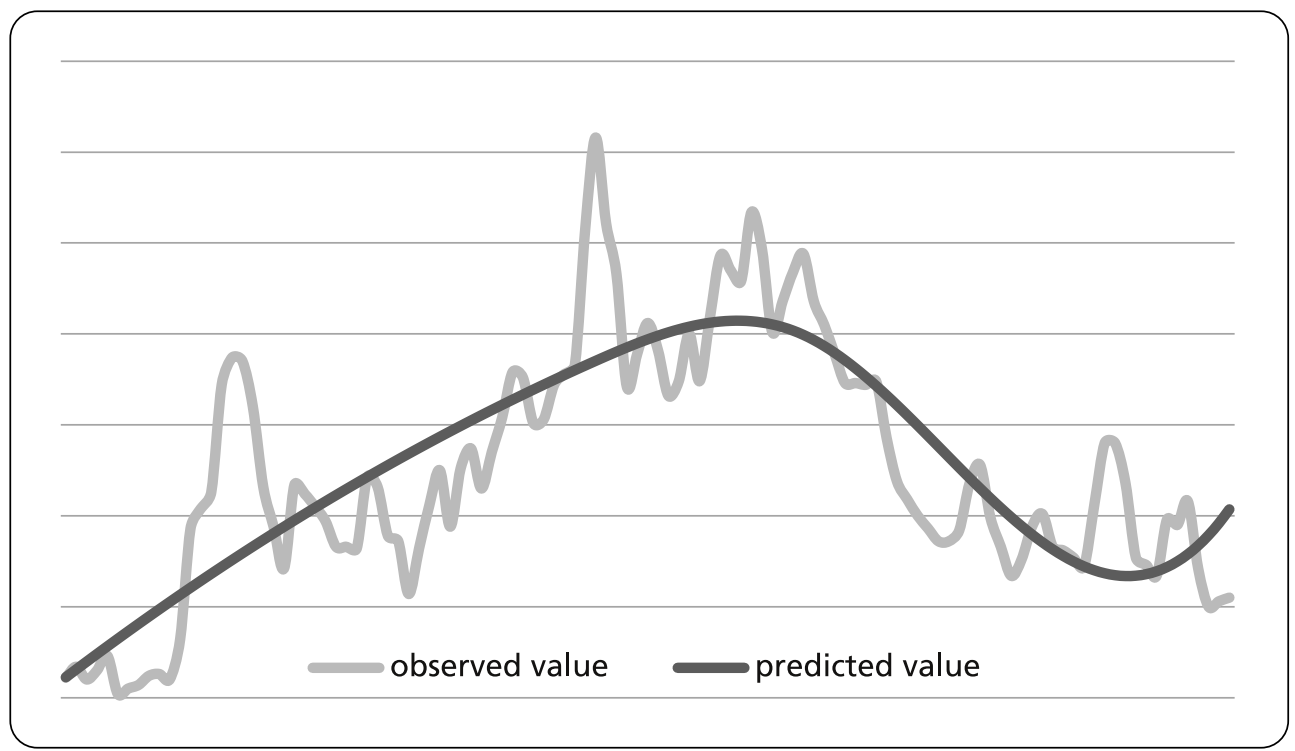

The shape of the life cycle deduced from this spline function model is distinguishable enough to decide whether or not it corresponds with the Downs's model. Despite being a non-ecological issue, the media attention cycle of the beef imports issue does correspond with the Downs issue attention model. This means that Downs's concept of an issue attention cycle may work for other issues or public events besides ecological issues.

\section{The Issue Competition Model}

As Hilgartner and Bosk's (1988) concept of the competition of social problems suggests, different public events and issues seem to compete for media attention. Media attention to old issues or events declines because of the emergence of new issues or public events. Media attention to the beef imports issue also seems to have been affected by the appearance of new issues or public events. This paper develops an issue competition model and applies it to the beef imports issue, using the spline function to measure the decrease in media attention to old issues or public events (hereafter OIPE). It is supposed that the decrease is caused by the emergence of new issues or public events (hereafter NIPE).

The issue competition model has four steps in measuring a decrease in media attention to OIPE. The first step is to find the competition period by observing daily media 
attention to OIPE and NIPE. Competition between OIPE and NIPE is considered to exist when media attention to OIPE sharply declines just after the occurrence of NIPE. The OIPE may disappear or may attract media attention again. If an OIPE disappears after a NIPE occurs, the competition period is considered to last from the advent of the NIPE to the extinction of the OIPE. In the case of resurgence of the OIPE, the competition period lasts from the advent of the NIPE to the time when the OIPE arrives at the second highest point.

The second step is to develop and estimate the spline function explaining the observation values of media attention to OIPE. The development of this kind of spline function model is an outpost work to develop a conjecture model to calculate the extent of change in media attention to the OIPE under the assumption that no NIPE occurs. This spline function model is developed in the same way as the model that this study developed to ascertain whether or not the beef imports issue passed through a Downs cycle. The model developed in this step is measured by observation values of media attention to the OIPE. Whether or not the model estimated represents the actual cycle of the OIPE is judged by the value of the goodness of fit. If the goodness of fit of the model is not significant, it means that the model does not represent the actual cycle. If it does not portray the actual cycle, it is not useful for developing the conjecture model in the third step. Thus, the conjecture model can only be achieved if the goodness of fit of the spline function model is significant.

In the third step of the issue competition model, the conjecture model is developed and estimated. The conjecture model must represent media attention to the OIPE appropriately, assuming no NIPE emerges. In this step, the period of issue competition is introduced as an important notion. This period, a competition term of the OIPE and NIPE, is acquired by observing their media attention. The conjecture model can be developed by using media attention to the OIPE, which is omitted during the period of issue competition as the dependent variable.

The last step is to calculate the decrease in media attention to the OIPE that is caused by the emergence of the NIPE. It can be calculated by comparing the predicted value in the conjecture model and the observed value of media attention to the OIPE during the competition period. The decrease of the OIPE is the difference between the predicted value in the conjecture model and the observed value of the OIPE during the period.

\section{Application of the Issue Competition Model to the Beef Imports Issue}

This study calculates a decrease in media attention to the beef imports issue by using the competition model. In order to calculate the extent of the decrease, a NIPE 
should be found during the life cycle of the beef imports issue. Three such NIPEs were found: the strife between Korea and Japan over possession of Dokdo island; the killing of a traveler by a North Korean soldier in Gumgang Mt., and the designation of a chairman for the Korea Communications Commission who was not considered politically impartial. Figure 3 shows that media attention to the beef imports issue (the OIPE) declined as the NIPEs emerged. This paper develops the issue competition model with NIPE, which is the sum of media attention to an issue and two events.

Figure 3. Media Attention to Old and New Issues and Public Events

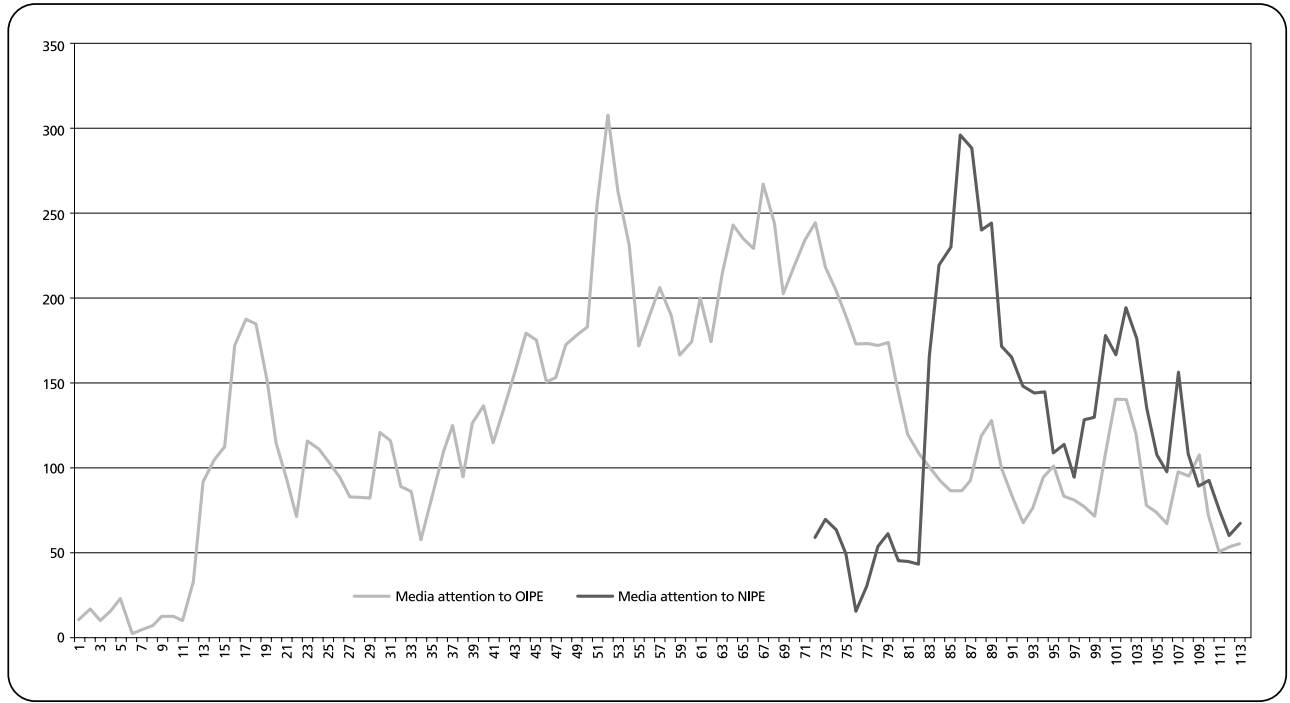

\section{Development and Estimation of the Issue Competition Model}

The first step in applying the issue competition model is to define the competition period by observing daily media attention to the OIPE and NIPE. Figure 3 shows that the competition between OIPE and NIPE came into existence during the period July 1-31. The second step is to develop the spline function reflecting the life cycle of the OIPE. This step was already carried out (see table 1). In the next step, the conjecture model is developed and estimated. Because the period of issue competition between the OIPE and NIPE was July 1-31, the conjecture model can be developed by using the OIPE life cycle with media attention during July 1-31 is omitted. In the first spline function developed before, I used observed values of the beef imports issue from April 21 to August 11 as the dependent variable. Yet I used observed values of the beef imports issue whose values of the competition period among its total life were omitted 
as the dependent variable in the conjecture model. Table 2 shows the conjecture model estimates.

Table 2. Estimation Results of the Conjecture Model

\begin{tabular}{c|c|c|c}
\hline $\begin{array}{c}\text { Independent variable } \\
\text { and constant }\end{array}$ & $\begin{array}{c}\text { Standardized regression } \\
\text { coefficients }\end{array}$ & T value & Significance level \\
\hline Constant & -8.812 & -0.450 & 0.712 \\
\hline$Z_{1}$ & $3.097^{* * *}$ & 3.123 & 0.003 \\
\hline$Z_{2}$ & $-5.633^{*}$ & -1.809 & 0.074 \\
\hline$Z_{3}$ & -110.005 & -0.391 & 0.697 \\
\hline$Z_{4}$ & $6.606 *$ & 1.824 & 0.072 \\
\hline$Z_{5}$ & $-71.168^{* *}$ & -2.094 & 0.040 \\
\hline$Z_{6}$ & $-43.763^{* * *}$ & -3.791 & 0.000 \\
\hline$Z_{7}$ & -5.998 & -2.748 & 0.007 \\
\hline$Z_{8}$ & $2.020 * *$ & 2.389 & 0.019 \\
\hline
\end{tabular}

${ }^{*} p<0.1 ;{ }^{* *} p<0.05 ;{ }^{* * *} p<0.01 . F=46.624 . R^{2}=0.671$.

The estimation results of the conjecture model show that six of eight independent variables are statistically significant; the goodness of fit is thus good; the value of $\mathrm{R}^{2}$ has an explanation power of 67.1 percent. The predicted value obtained from the estimation of the conjecture model is shown in figure 4.

Figure 4. Observed Value and Value Predicted by the Conjecture Model

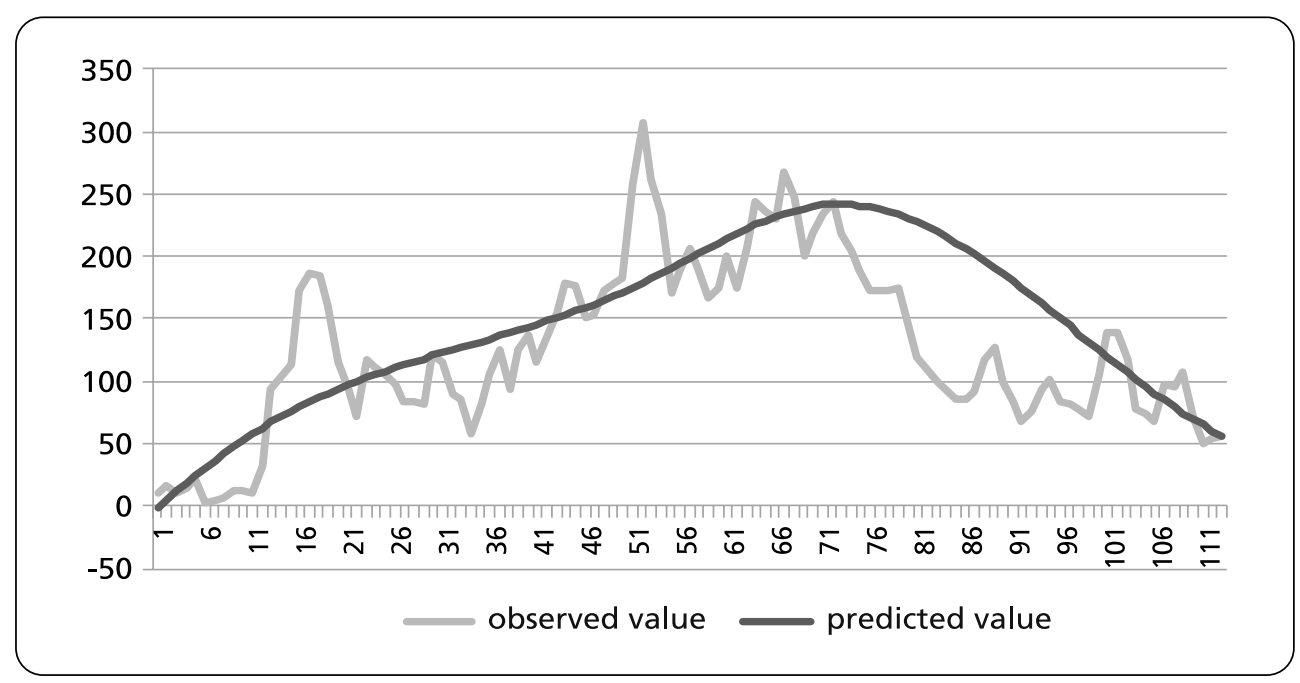




\section{Calculation of the Decrease in Media Attention to the OIPE}

The last step of the issue competition model is to calculate the decrease in media attention to the OIPE that is caused by the emergence of the NIPE. The issue competition model showed that the amount of the decrease was the difference between the predicted value in the conjecture model and the observed value of the OIPE during the competition period. Table 3 shows the difference between these two values from July 1-31.

Table 3. Decrease in Media Attention to Old Issues and Public Events

\begin{tabular}{|c|c|c|c|}
\hline Competition period & Predicted value & Observed value & Amount of decrease \\
\hline July 1 & 241.79 & 244 & -2.21 \\
\hline 2 & 241.91 & 218 & 23.91 \\
\hline 3 & 241.55 & 205 & 36.55 \\
\hline 4 & 240.72 & 189 & 51.72 \\
\hline 5 & 239.44 & 173 & 66.44 \\
\hline 6 & 237.74 & 173 & 64.74 \\
\hline 7 & 235.63 & 172 & 63.63 \\
\hline 8 & 233.13 & 174 & 59.13 \\
\hline 9 & 230.26 & 143 & 87.26 \\
\hline 10 & 227.05 & 119 & 108.05 \\
\hline 11 & 223.50 & 109 & 114.50 \\
\hline 12 & 219.65 & 100 & 119.65 \\
\hline 13 & 215.50 & 93 & 122.50 \\
\hline 14 & 211.09 & 86 & 125.09 \\
\hline 15 & 206.42 & 86 & 120.42 \\
\hline 16 & 201.52 & 92 & 109.52 \\
\hline 17 & 196.41 & 118 & 78.41 \\
\hline 18 & 191.10 & 128 & 63.10 \\
\hline 19 & 185.63 & 99 & 86.63 \\
\hline 20 & 179.99 & 83 & 96.99 \\
\hline 21 & 174.23 & 67 & 107.23 \\
\hline 22 & 168.35 & 76 & 92.35 \\
\hline 23 & 162.37 & 94 & 68.37 \\
\hline 24 & 156.32 & 101 & 55.32 \\
\hline 25 & 150.21 & 83 & 67.21 \\
\hline 26 & 144.07 & 81 & 63.07 \\
\hline 27 & 137.91 & 77 & 60.91 \\
\hline 28 & 131.75 & 72 & 59.75 \\
\hline 29 & 125.61 & 106 & 19.61 \\
\hline 30 & 119.52 & 140 & -20.48 \\
\hline 31 & 113.49 & 140 & -26.51 \\
\hline Total & $5,983.88$ & 3,841 & $2,142.88$ \\
\hline
\end{tabular}


Table 3 shows how much media attention to the beef imports issue would decrease by the emergence of the Dokdo dispute, the murder in Gumgang Mt., and the Korea Communications Commission appointment. The total decrease in media attention to the beef imports issue was $2,142.88$. This means that the number of daily newspaper articles on the beef imports issue declined with the appearance of the new issue and events during July 1-31.

Media attention to the beef imports issue began to decline 70 days after it started. This period of 70 days can be the time when the public feels fatigue on the issue. Therefore, we can say that the media attention to the issue would decline without their emergence. From the point of view of the fatigue of media attention, we can conclude that the emergence of these three issues would play a role in the decline of media attention to the beef imports issue.

\section{CONCLUSION}

This paper tested Downs's idea empirically and presented a new idea, showing why the life cycle of an issue was extended, by applying it to the beef imports issue. In order to determine whether or not Downs's idea works for the media attention cycle, this paper applied the spline function to help distinguish whether or not an issue's life cycle passes through the Downsian cycle. Even though Downs's idea focused on the public attention cycle for ecological issues, it worked well for a media attention cycle on a non-ecological issue.

The beef imports issue that emerged in South Korea in 2008 was a major issue with a comparatively long life cycle, 112 days. This paper showed that small issues and events related to the big issue played an important role in prolonging its life cycle. The beef imports controversy involved the issue of mad cow disease and four events (coverage on the TV show PD Pocketbook, excessive use of force by the police, intimidation of companies advertising in conservative newspapers).

This study contributes to academic studies of media attention to issues and events through the development and empirical estimation of the issue competition model. It presents a new notion of the issue competition model which calculates the extent of the decrease in media attention to old issues and events by the emergence of new issues and events. The spline function was used to develop the issue competition model. The adoption of the dependent variable in which observed values were omitted during the competition period in the spline function was very helpful in getting a new foundation. When I used this dependent variable, I found that the estimated values of the spline function would draw the life cycle of an issue or event without the emergence 
of new competition issues. I hope that this idea will contribute to the development of methodology in this area.

This paper calculated the extent of the decrease in media attention to the beef imports issue caused by the appearance of the Dokdo dispute, the murder in Gumgang Mt., and the appointment to the Korea Communications Commission. It showed that the emergence of these issue and events would lead to a decrease in the number of daily newspaper articles on the beef imports issue by 2,142 during the period from July 1-31, 2008.

\section{REFERENCES}

Blumer, H. 1971. Social problems as collective behavior. Social Problems, 18: 298-306.

Connolly, W. E. 1983. The terms of political discourse (2d ed.). Princeton, NJ: Princeton University Press.

Cram, L. 2001. Whither the Commission? Reform, renewal and the issue-attention cycle. European Public Policy, 8(5): 770-786.

Downs, A. 1972. Up and down with ecology - the issue attention cycle. Public Interests, 28(Summer): 38-50.

Erbring, L., Goldenberg, E. N., \& Miller, A. H. 1980. Front-page news and real-world cues: A new look at agenda-setting by the media. American Journal of Political Science, 24(1): 16-49.

Gallie, W. B. 1962. Essentially contested concepts. Proceedings of the Aristotelian Society, 56: 169.

Gamson, W. A., \& Modigliani, A. 1989. Media discourse and public opinion on nuclear power: A constructionist approach. American Journal of Sociology, 95: $1-37$.

Gamson, W. A., \& Wolfsfeld, G. 1993. Movements and media as interacting system. Annals of the American Academy of Political and Social Science, 528: 114-125.

Gans, H. J. 1979. Deciding what's news. New York: Pantheon.

. 1980. Deciding what's news: A study of CBS Evening News, NBC Nightly News, Newsweek and Time. New York: Vintage.

Hall, C. M. 2002. Travel safety, terrorism, and the media: The significance of the issue-attention cycle. Current Issues in Tourism, 5(5): 458-446.

Hilgartner, S., \& Bosk, C. L. 1988. The rise and fall of social problems: A public arenas model. American Journal of Sociology, 94(1): 53-78.

Kielbowicz, R. B., \& Scherer, C. 1986. The role of the press in the dynamics of social movements. Research in Social Movements, Conflicts and Change, 9: 71-96. 
Korea Integrated News Database System. http://www.kinds.or.kr/.

McCarthy, J. D., McPhail, C., \& Smith, J. 1996. Images of protest: Dimensions of selection bias in media coverage of Washington D.C. demonstrations, 1982 and 1992. American Sociological Review, 61: 478-499.

McCombs, M. 2004. Setting the agenda: The mass media and public opinion. Polity Press.

Molotch, H. 1979. Media and movements. In M. N. Zald \& J. D. McCarthy (eds.), The dynamics of social movements (pp. 71-93). Cambridge, MA: Winthrop.

Molotch, H., \& Lester, M. 1974. News as purposive behavior: On the strategic uses of routine events, accidents, and scandals. American Sociological Review, 39: 101-112.

Olien, C. N., Tichenor, P. J., and Donahue, G. A. 1992. Media coverage and social movements. In C. T. Salmon (ed.), Information campaigns: Balancing social values and social change. Newbury Park, CA: Sage.

Oliver, P. E. 1989. Bringing the crowd back in: The nonorganizational elements of social movements. Research in Social Movements, Conflicts and Change, 11:1-30.

Oliver, P. E., \& Maney, G. M. 2000. Political processes and local newspaper coverage of protest events: From selection bias to triadic interactions. American Journal of Sociology, 106(2): 463-505.

Son, Y. J., \& Weaver, D. H. 2006. Another look at what moves public opinion: Media agenda setting and polls in the 2000 U.S. election. International Journal of Public Opinion Research, 18(2): 174-197.

Zald, M. N. 1996. Culture, ideology, and strategic framing. In D. McAdam, J. D. McCarthy, \& M. N. Zald (eds.), Comparative perspectives on social movements: Political opportunities, mobilizing structure, and cultural framings (pp. 261-274). New York: Cambridge University Press. 